\title{
Effects of grazing on the structure of mid-shore, intertidal assemblages on moderately exposed rocky shores of the Swedish west coast
}

\author{
M. Lindegarth ${ }^{1, *}$, P. Åberg' ${ }^{2}$, G. Cervin ${ }^{2}$, P. G. Nilsson ${ }^{3}$ \\ ${ }^{1}$ Centre for Research on Ecological Impacts of Coastal Cities, Marine Ecology Laboratories, A11, University of Sydney, \\ New South Wales 2006, Australia \\ ${ }^{2}$ Department of Marine Botany, Göteborg University, Box 461, 40530 Göteborg, Sweden \\ ${ }^{3}$ Tjärnö Marine Biological Laboratory, 45296 Strömstad, Sweden
}

\begin{abstract}
A manipulative experiment was done on the Swedish west coast to test hypotheses about effects of grazing on assemblages of algae and sessile animals on moderately exposed shores. The experiments, which lasted for $15 \mathrm{mo}$, involved a total of 144 experimental units at 16 sites in 2 areas $3 \mathrm{~km}$ apart. Experimental treatments involved fences to exclude grazing snails, open fences to control for effects of fences, and control areas, which were not manipulated in any way. In contrast to results from moderately exposed shores in other parts of the world and in contrast to sheltered areas in the region, grazers did not appear to significantly influence the structure and composition of these assemblages. Fences and manual removal of snails were only partly successful in removing grazers. Additional observational evidence, however, supports the conclusion that grazers have a limited impact on structure and abundance of these intertidal assemblages.
\end{abstract}

KEY WORDS: Grazer exclusion · Field experiment $\cdot$ Community structure $\cdot$ Rocky shore ecology · Littorina spp. · Sweden

Resale or republication not permitted without written consent of the publisher

\section{INTRODUCTION}

Grazing by gastropod limpets and snails influence the structure and composition of assemblages of plants and animals on rocky shores around the world (e.g. Hawkins 1981, Underwood \& Jernakoff 1981, Lubchenco 1983). Models invoking variable rates of grazing from gastropods have been proposed to explain observations of small-scale patchiness and vertical zonation, as well as large-scale latitudinal variability in assemblages on rocky shores (Lubchenco \& Gaines 1981, Hawkins \& Hartnoll 1983, Foster 1992, Hawkins et al. 1992, Vadas \& Elner 1992).

The effect of limpets on algal cover at mid-tide levels of the British Isles is an example of how grazing can

\footnotetext{
*Present address: Tjärnö Marine Biological Laboratory, 45296 Strömstad, Sweden. E-mail: mali@tmbl.gu.se
}

play a major role in structuring rocky shore assemblages (reviewed in Hawkins \& Hartnoll 1983, Hawkins et al. 1992). It has repeatedly been shown that limpets prevent the establishment of ephemeral algae and subsequent dense covers of Fucus spp. in moderately exposed sites along British shores. Limpets Patella sp. do not occur in the intertidal zone of the Swedish west coast. Littorinid snails, mainly Littorina saxatilis and $L$. littorea, are, however, very abundant on most Swedish shores. These species are often found together but the former species is more abundant on exposed shores, while the larger densities of the latter are commonly found in sheltered areas (pers. obs.). Littorinid snails can consume epilithic micro-algae, ephemeral filamentous or foliose algae and macro-algae (Norton et al. 1990). Several studies in other parts of the world have shown that grazing by L. littorea may affect the density and structure of assemblages of plants and ani- 
mals in sheltered to moderately sheltered areas (Lubchenco 1978, Lein 1980, Keser et al. 1981, Bertness et al. 1983, Petraitis 1983, Keser \& Larson 1984). Correlative approaches suggest that $L$. saxatilis may influence the cover and structure of intertidal assemblages (Hawkins \& Hartnoll 1983, Johannesson 1989). Furthermore, in Britain it has been suggested that the ecologically similar L. neglecta controls the cover of ephemeral green algae (Hawkins 1981). It has been hypothesized that effects of these types of grazers occur only in the presence of barnacles, which are thought to provide refuges for the snails (Raffaelli \& Hughes 1978).

There are few published quantitative observations of spatial and temporal patterns of variability in structure and composition of intertidal rocky shores on the Swedish west coast. Early qualitative observations were typically concerned with classification of algal 'communities' (Kyhlin 1918, Lewis 1965, Söderström 1965, Aleem 1969), rather than finding the causes of observed patterns. Conspicuous features of assemblages on Swedish shores are the large seasonal variability and the compressed vertical gradients due to the small tidal amplitude (less than $30 \mathrm{~cm}$ ). Previous models to explain patterns of algal assemblages on shores in this part of the world have stressed stochastic processes, such as ice-scouring (Åberg 1992) and unpredictable changes in the level of water (Johannesson 1989). Until recently, little attention has been paid to the role of ecological processes, such as competition, grazing and predation, thought to be important structuring forces in other areas. These recent manipulative experiments, however, suggested that grazing by Littorina littorea may affect the cover of ephemeral green algae (Lein 1980) and the recruitment of the fucoid Ascophyllum nodosum in sheltered areas (Cervin \& Åberg 1997, Viejo et al. 1999). This experiment attempts to test whether grazing may be important also in moderately exposed areas and whether grazing affects whole assemblages. If this was true, we predicted that assemblages in patches from which grazers were excluded would change in a different way than assemblages in patches to which grazers had access. Because the composition of assemblages, the activity and abundance of snails (Underwood \& Chapman 1996), supply of recruits and numerous ecological and physical processes vary among places and among times (e.g. Hawkins 1981, Underwood \& Anderson 1994), we also predicted that effects of grazing would differ among places and times. The detection of such interactive effects of grazing and spatial and temporal scales requires more complex designs than previously attempted in experiments on similar types of shores.

\section{MATERIALS AND METHODS}

Study area. The experiment was done in moderately exposed sites in 2 areas, Svartskären and the southern Koster area south of Tjärnö Marine Biological Laboratory (TMBL) on the Swedish west coast $\left(58^{\circ} 54^{\prime} \mathrm{N}\right.$,

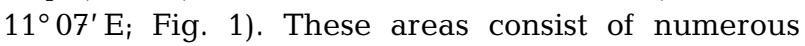
granite islands and islets. As explained in detail below, 8 sites were established in each of these 2 areas. Experiments were started on individual dates at different sites between 6 and 26 August 1996 and between 18 March and 27 April 1997. Each site was selected

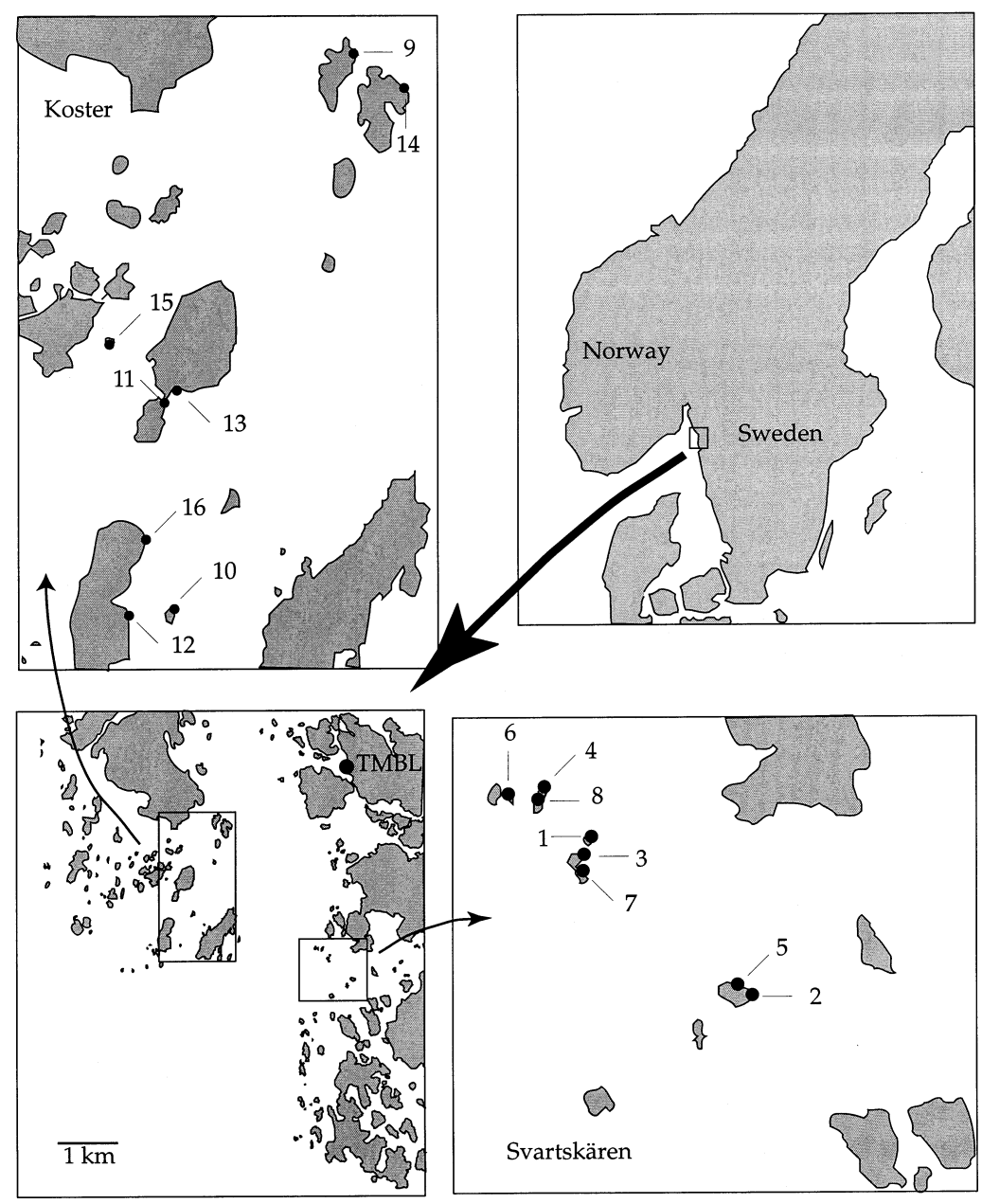

Fig. 1. Map of area and positions of individual sites. TMBL: Tjärnö Marine Biological Laboratory 
haphazardly from a number of possible sites within a set of criteria: (1) facing east to north-east, (2) having an inclination of between 15 and $45^{\circ}$, (3) having a simple topography (i.e. thus preventing snails to pass under the fences), and (4) having an extensive cover (>50\%) of the barnacle Semibalanus balanoides.

General hypotheses. This experiment was designed to test hypotheses derived from the general model that grazers, mainly the snails Littorina saxatilis and L. littorea, affect the structure of assemblages on moderately exposed rocky shores on the west coast of Sweden. We predicted that assemblages of animals and plants, in quadrats $(0.5 \times 0.5 \mathrm{~m})$ from which snails were excluded with fences (FE), would change differently from assemblages in control quadrats (CO) from which snails were not excluded $(\mathrm{CO} \neq \mathrm{FE})$. Fences were made of stainless steel mesh (mesh-size $0.5 \mathrm{~cm}$ ) and were $5 \mathrm{~cm}$ high. Fences may, however, also change the flow of water, moisture, shading etc., which may affect assemblages of plants and animals (Underwood 1980, Benedetti-Cecchi \& Cinelli 1997). Therefore, we used open fences (OF) as procedural controls for the fences. Open fences were constructed from four $0.3 \times 0.05 \mathrm{~m}$ pieces of mesh. Each of these were bent to form a right angle and placed in the 4 corners. Thus, each side of the open quadrats consisted of $30 \mathrm{~cm}$ fence, while $20 \mathrm{~cm}$ was open to allow snails to move freely in and out. Both types of fence were attached to the granite rock using 16 stainless steel screws with plastic plugs, while control quadrats were marked with 2 screws. Thus, except for allowing access to snails, we hypothesized that the open fences had the same properties as the closed fences and that they differed from normal control quadrats only by having structures around them. Consequently, if the presence of snails affects assemblages on these shores, we predicted that assemblages in the open fences would not differ from those in control quadrats, but assemblages in both these types of quadrat would differ from those in quadrats with fences $(\mathrm{CO}=\mathrm{OF} \neq \mathrm{FE})$. If, on the other hand, fences affect assemblages in other ways than excluding grazers, we expected assemblages in open fences to be similar to those within fences but different from those in control quadrats $(\mathrm{CO} \neq \mathrm{OF}=\mathrm{FE})$.

In each of 2 seasons ('Se', autumn 1996 and spring 1997, fixed factor) and at 2 dates ('Da', random factor) within each season, we established 2 sites ('Si', 100 to $1000 \mathrm{~m}$ apart, random factor) in 2 areas ('Ar', 3 km apart, random factor), each with 3 quadrats per treatment (' $\mathrm{Tr}^{\prime}$, 1 to $10 \mathrm{~m}$ apart, fixed factor). This experimental design allows evaluation of how the effects of grazers differ among areas $(\operatorname{Tr} \times \mathrm{Ar})$, among sites $(\mathrm{Tr} \times \mathrm{Si})$, among seasons and dates when the experiment was initiated $(\operatorname{Tr} \times$ Se and $\operatorname{Tr} \times \mathrm{Da}[\mathrm{Ar}$, Se] $)$ and, finally, among different combinations of seasons and areas $(\operatorname{Tr} \times \mathrm{Se} \times \mathrm{Ar})$.
Sampling. The experiment was run from 6 August 1996 to 30 October 1997 (15 mo). Quadrats were sampled with the point method using a regular $7 \times 7$ point grid. Samples were taken once a month for the first 3 mo. Subsequent sampling was less frequent. Due to rough seas, ice and cold weather, the timing of sampling could not be fully controlled. Sampling was usually done when quadrats were emersed during low tide. On a few occasions, however, samples had to be taken using a scuba mask. Furthermore, the number of sampling times differed among sites because sites were established in 2 seasons and at a number of dates. Therefore, the number of sampling dates ranged from 7 to 4 and the time between the initiation and end of the experiment varied from 6 to 15 mo. Algae and sessile animals were usually identified in the field. Upon the encounter of ambiguous species of algae, similar specimens were collected from outside the experimental quadrats and identified in the laboratory. The taxonomic resolution varied among groups. Algae were identified to species or family and animals were usually identified to species.

Analytical techniques. Temporal and spatial variability in structure and composition of intertidal assemblages were visualized using non-metric multidimensional scaling (n-MDS) of Bray-Curtis dissimilarities of fourth-root transformed data using the software package Plymouth Routines in Multivariate Ecological Research (PRIMER) (Clarke \& Warwick 1994). PRIMER was also used to evaluate multivariate patterns of spatial and temporal variability with the Similarity Percentage Breakdown Procedure (SIMPER) routine. This method is used to evaluate which component of the assemblages contributed most to observed dissimilarities among samples or groups of samples.

Hypotheses of effects of grazers were tested using analysis of variance (ANOVA). We predicted that the exclusion of grazers would cause assemblages in fenced quadrats to change differently from assemblages in quadrats with open fences or control quadrats. To test this hypothesis, we calculated Bray-Curtis dissimilarities individually for each quadrat between (1) the date of initiation and the summer of 1997, and (2) the date of initiation and the winter of 1997 . These 2 types of Bray-Curtis dissimilarities represent quantitative estimates of change in structure of assemblages between times, and they were each analyzed separately using ANOVA. Bray-Curtis dissimilarity is a useful and sensitive metric for detecting changes in the structure and composition of complex assemblages of animals and plants (e.g. Clarke \& Warwick 1994). Dissimilarities were calculated using fourth-root transformed data. Similarly, for each quadrat we calculated the changes in total cover of algae, amount of bare rock and cover of crustose algae. These changes were also subsequently analyzed using ANOVA. 
This approach was chosen because it allowed us to test hypotheses about temporal changes in a straightforward way, using 1 independent replicate from each quadrat within each analysis. It is, however, important to point out that the time during which the estimated changes occurred differed among seasons and to some extent among dates, within each of these analyses. For instance, in the first analysis some dissimilarities (Season 1) were calculated between autumn 1996 and summer 1997 (11.5 mo) and others (Season 2) were calculated between spring 1997 and summer 1997 (3.5 mo). In spite of these differences, we chose to incorporate both seasons in the same analyses in order to maximize the number of degrees of freedom and power in our tests. In practice, this procedure means that effects of the experimental treatment are likely to vary among seasons and dates, i.e. there will be significant interactions rather than simple effects of the experimental treatments. Such interactions were interpreted a posteriori using Student-Newman-Keuls (SNK) procedure. Furthermore, we applied a posteriori elimination and pooling of non-significant ( $p>0.25)$ components of variability to increase power of tests (Underwood 1997). Variances were tested for heterogeneity using Cochran's test statistic, $C$.

\section{RESULTS}

\section{General observations}

During the experiment we identified 35 sedentary taxa of algae and animals. The most abundant taxa were barnacles Semibalanus balanoides (average cover $46 \%$ and occurring in $91 \%$ of the quadrats, i.e. with frequency 0.91), mussels Mytilus edulis (21\% and 0.67), filamentous red algae Polysiphonia sp. and Ceramium sp. (15\% and 0.50$)$, and crustose red algae Hildenbrandia rubra (10\% and 0.58$)$. The overall average percentage of bare rock was $12 \%$, occurring with a frequency of 0.69 . There were clear differences in initial assemblages between the 2 seasons (Fig. 2). Plots which were established in the spring 1997 had a larger cover of foliose red algae Bangia atropurpurea, ephemeral green algae Urospora sp. and Ulothrix sp. and mussels $M$. edulis, but a smaller cover of filamentous red Ceramium sp. and Polysiphonia sp., the red alga Nemalion multifidum and crusts $H$. rubra compared plots established in the autumn 1996. Assemblages also tended to differ among shores, but these differences appeared smaller than differences between seasons (Fig. 2).

It was also evident during the course of the experiment that the fences used in this experiment were not entirely successful in excluding small individuals of

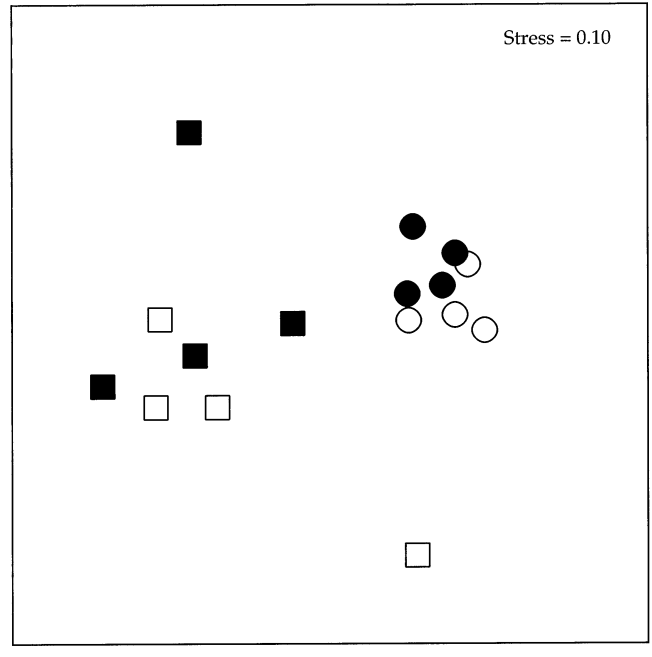

Fig. 2. Non-metric multidimensional scaling (n-MDS) plot of differences among assemblages at the start of the experiment. Empty symbols: sites in Svartskären; filled symbols: sites in the Koster area; circles: sites established in the autumn 1996; and squares: sites established in spring 1997. Each symbol represents an average of all quadrats at 1 site

Littorina saxatilis. Therefore, individuals which had entered the fences were removed during sampling and on 5 other occasions. Quantitative data were not collected systematically to estimate accurately the abundances of snails or the persistence of each manual removal of snails. The existing data (from 20 August 1996), however, suggest that on average 190 small $L$. saxatilis (length $<5 \mathrm{~mm}$ ) were removed from inside caged quadrats (largest number in 1 quadrat $=500$ ). Large individuals of $L$. saxatilis and $L$. littorea were seldom found inside the fences but were usually found at densities of 1 to 2 snails per quadrat for controls and open fences.

\section{Effects of experimental manipulations}

Changes in the structure and composition of intertidal assemblages, measured as Bray-Curtis dissimilarity, differed significantly among experimental treatments at some sites and dates (Table 1a,e, Fig. 3). In July 1997 there was a significant interaction between 'Treatments' and 'Sites' (Table 1a). Dissimilarities were smaller inside fences than in open fences and control quadrats at Site 9 in the Koster area (SNK-test, $\mathrm{FE}<\mathrm{OF}=\mathrm{CO}$ ). In no other site were there significant differences among treatments. Analyses using SIMPER revealed that dissimilarities at this site were mainly caused by decreases in cover of filamentous red algae, Hildenbrandia rubra, Nemalion multifidum and bare rock and increased cover of the mussel Mytilus edulis. 
Table 1. Analyses of variance on and change in structure of assemblages (a-d) from the start of the experiment to July 1997 and $(\mathrm{e}-\mathrm{h})$ from the start to November 1997. E-T: error-term used to construct F-ratios. For some tests involving the experimental treatment, a pooled MS was used as error-term. The components in pooled MS are indicated as p (component 1, component 2, ...). ns: not significant

\begin{tabular}{|c|c|c|c|c|c|c|c|c|c|c|}
\hline \multirow[t]{2}{*}{ Source } & \multirow[t]{2}{*}{ df } & \multirow[t]{2}{*}{ E-T } & \multicolumn{2}{|c|}{ (a) Dissimilarity } & \multicolumn{2}{|c|}{ (b) Algal cover } & \multicolumn{2}{|c|}{ (c) Bare rock } & \multicolumn{2}{|l|}{ (d) Crusts } \\
\hline & & & MS & $\mathrm{p}$ & MS & $\mathrm{p}$ & MS & $\mathrm{p}$ & MS & $\mathrm{p}$ \\
\hline \multicolumn{11}{|l|}{ July 1997} \\
\hline $\mathrm{i} \quad$ Area $=\mathrm{Ar}$ & 1 & vii & 1.9 & ns & 1.75 & ns & 0.03 & ns & 0.03 & ns \\
\hline ii $\quad$ Season $=\mathrm{Se}$ & 1 & iv & 32.8 & ns & 0.08 & ns & 0.04 & ns & 0.03 & ns \\
\hline iii $\quad$ Treatment $=\operatorname{Tr}$ & 2 & $\mathrm{v}$ & $141^{\mathrm{p}(\mathrm{xii}, \mathrm{xi}, \mathrm{viii})}$ & ns & $0.08^{p(x i i, x i, ~ v i i i) ~}$ & ns & $0.05^{\mathrm{p}(\mathrm{x}, \mathrm{viii}, \mathrm{v})}$ & ns & $0.00^{p(x i i, x i, x, v)}$ & ns \\
\hline iv $\quad \mathrm{Se} \times \mathrm{Ar}$ & 1 & vii & 62.6 & ns & 0.31 & ns & 0.47 & ns & 0.04 & ns \\
\hline $\mathrm{v} \quad \operatorname{Tr} \times \mathrm{Ar}$ & 2 & $\mathrm{x}$ & $308^{p(x i, x)}$ & ns & $0.35^{\mathrm{p}(\mathrm{xi}, \mathrm{x})}$ & ns & 0.03 & ns & $0.01 \mathrm{p}(\mathrm{xii}, \mathrm{xi}, \mathrm{x})$ & ns \\
\hline vi $\operatorname{Tr} \times \mathrm{Se}$ & 2 & viii & $534 \mathrm{p}(\mathrm{xi}, \mathrm{x}$, viii $)$ & ns & $0.05^{\mathrm{p}(\mathrm{xi}, \mathrm{x}, \mathrm{viii})}$ & ns & 0.00 & ns & 0.02 & ns \\
\hline vii Date $=\mathrm{Da}(\mathrm{Ar}, \mathrm{Se})$ & 4 & ix & 761 & ns & 0.96 & ns & 0.08 & ns & 0.01 & $\mathrm{~ns}$ \\
\hline viii $\operatorname{Tr} \times \mathrm{Se} \times \mathrm{Ar}$ & 2 & $\mathrm{x}$ & $148^{p(x i, x)}$ & ns & $0.25^{\mathrm{p}(\mathrm{xi}, \mathrm{x})}$ & ns & 0.03 & ns & $0.03^{p(x i i, x i, x)}$ & ns \\
\hline ix $\quad$ Site $=\mathrm{Si}(\mathrm{Ar}, \mathrm{Se}, \mathrm{Da})$ & 8 & xii & 675 & $<0.01$ & 0.28 & $<0.01$ & 0.07 & $<0.01$ & 0.01 & ns \\
\hline $\mathrm{x} \quad \operatorname{Tr} \times \mathrm{Da}(\mathrm{Ar}, \mathrm{Se})$ & 8 & xi & 115 & $\mathrm{~ns}$ & 0.15 & ns & 0.05 p (xii, xi) & $<0.05$ & $0.01 \mathrm{p}(\mathrm{xii}, \mathrm{xi})$ & ns \\
\hline xi $\operatorname{Tr} \times \operatorname{Si}(\mathrm{Ar}, \mathrm{Se}, \mathrm{Da})$ & 16 & xii & 309 & $<0.05$ & 0.27 & $<0.05$ & 0.02 & ns & 0.01 & ns \\
\hline xii Residual & 96 & & 173 & & 0.11 & & 0.02 & & 0.01 & \\
\hline \multirow[t]{2}{*}{ Source } & \multirow[t]{2}{*}{$\mathrm{df}$} & \multirow[t]{2}{*}{$\mathrm{E}-\mathrm{T}$} & \multicolumn{2}{|c|}{ (e) Dissimilarity } & \multicolumn{2}{|l|}{ (f) Algal cover } & \multicolumn{2}{|c|}{ (g) Bare rock } & \multicolumn{2}{|l|}{ (h) Crusts } \\
\hline & & & MS & $\mathrm{p}$ & MS & $\mathrm{p}$ & $\mathrm{MS}$ & $\mathrm{p}$ & $\mathrm{MS}$ & $\mathrm{p}$ \\
\hline \multicolumn{11}{|l|}{ November 1997} \\
\hline i $\quad$ Area $=A r$ & 1 & vii & 1250 & ns & 3.05 & ns & 0.06 & ns & 0.45 & ns \\
\hline ii $\quad$ Season $=\mathrm{Se}$ & 1 & iv & 6192 & ns & 2.95 & ns & 0.33 & ns & 0.33 & ns \\
\hline iii $\quad$ Treatment $=\operatorname{Tr}$ & 2 & $\mathrm{v}$ & $12.4 \mathrm{p}(\mathrm{x}, \mathrm{viii}, \mathrm{v})$ & ns & 0.00 p (xii, xi, $x$, vii, & , v) $\mathrm{ns}$ & $0.00^{\mathrm{p}(\mathrm{x}, \mathrm{viii}, \mathrm{v})}$ & ns & 0.01 & ns \\
\hline iv $\mathrm{Se} \times \mathrm{Ar}$ & 1 & vii & 466 & ns & 3.10 & ns & 0.19 & ns & 0.27 & ns \\
\hline $\mathrm{V} \quad \operatorname{Tr} \times \mathrm{Ar}$ & 2 & $\mathrm{x}$ & 9.90 & ns & $0.00 \mathrm{p} \mathrm{(xii,} \mathrm{xi,x)}$ & ns & 0.00 & ns & 0.07 & ns \\
\hline vi $\operatorname{Tr} \times \mathrm{Se}$ & 2 & viii & $142^{\mathrm{p}(\mathrm{x}, \mathrm{viii}, \mathrm{v})}$ & $\mathrm{ns}$ & $0.13 \mathrm{p}(\mathrm{xii}, \mathrm{xi}, \mathrm{x}, \mathrm{vii}$, & , v) $\mathrm{ns}$ & $0.02^{p(x, v i i i, v)}$ & ns & 0.00 & ns \\
\hline vii Date $=\mathrm{Da}(\mathrm{Ar}, \mathrm{Se})$ & 4 & ix & 1310 & ns & 1.39 & ns & 0.62 & $<0.01$ & 0.25 & ns \\
\hline viii $\operatorname{Tr} \times \mathrm{Se} \times \mathrm{Ar}$ & 2 & $\mathrm{x}$ & 110 & ns & $0.09 \mathrm{p}(\mathrm{xii}, \mathrm{xi}, \mathrm{x})$ & ns & 0.02 & ns & 0.07 & ns \\
\hline ix $\quad$ Site $=\mathrm{Si}(\mathrm{Ar}, \mathrm{Se}, \mathrm{Da})$ & 8 & xii & 796 & $<0.01$ & 3.29 & $<0.01$ & 0.05 & $<0.01$ & 0.18 & $<0.01$ \\
\hline $\mathrm{x} \quad \operatorname{Tr} \times \mathrm{Da}(\mathrm{Ar}, \mathrm{Se})$ & 8 & $\mathrm{xi}$ & $271^{p}(\mathrm{xii}, \mathrm{xi})$ & $<0.05$ & $0.10^{p(x i i, x i)}$ & ns & $0.03 \mathrm{p}$ (xii, xi) & ns & $0.03^{p(x i i, x i)}$ & ns \\
\hline xi $\operatorname{Tr} \times \operatorname{Si}(\mathrm{Ar}, \mathrm{Se}, \mathrm{Da})$ & 16 & xii & 47.6 & ns & 0.11 & ns & 0.02 & ns & 0.02 & ns \\
\hline xii Residual & 96 & & 113.6 & & 0.11 & & 0.02 & & 0.02 & \\
\hline
\end{tabular}

The cover of filamentous algae decreased slightly in the fenced quadrats compared to the other treatments. In November 1997 effects of the treatments on dissimilarities differed from those in July 1997. At this time of sampling, effects of the treatments differed depending on when the experiment was initiated, i.e. there was a significant interaction between 'Treatments' and 'Dates' (Table 1e). Differences could not be fully resolved using SNK-tests, but the largest difference among treatments occurred in Svartskären, in sites which were established at the first date in the autumn of 1996 (Sites 1 and 2, Fig. 3). The rank order of the experimental treatments was consistent at both sites (FE, $\mathrm{CO}$ and $\mathrm{OF}$ ). This indicates that assemblages in open fences were the ones that had changed the most followed by those in controls and in fenced plots. This order is not consistent with the predicted patterns indicating effects of grazing.

The change in total algal cover from the start of the experiment to July 1997 differed among treatments at some sites (' $\operatorname{Tr} \times \operatorname{Si}[\mathrm{Ar}, \mathrm{Se}, \mathrm{Da}]$ ', Table 1b). All affected sites were initiated in autumn 1996 (Fig. 4). At the first site at Svartskären the cover of algae had decreased inside fences, while there had been an increase in the open cages and controls (SNK, FE $<\mathrm{CO}=\mathrm{OF}$ ). At the second site in the same area, the algal cover in open fences had decreased significantly more than in fences and control plots (SNK, OF < CO = FE). Finally, at Site 10 in the Koster area, the percent cover had decreased significantly more inside fences compared to inside open fences and control plots (SNK, FE $<\mathrm{CO}=\mathrm{OF}$ ). While the results at 2 sites are consistent with the general prediction that assemblages in fences will differ from open fences and controls, they are contradictory to the hypothesis that exclusion of grazers will promote algal growth.

There was a significant interaction between the experimental treatments and starting date in the change of the amount of bare rock ('Tr $\times \mathrm{Da}[\mathrm{Ar}, \mathrm{Se}]$ ', Table 1c). SNK-tests did not reveal any significant differences among treatments at any date. There were, however, 3 instances of significant differences between dates for specific combinations of treatment, area and season. These differences cannot easily be interpreted as effects 

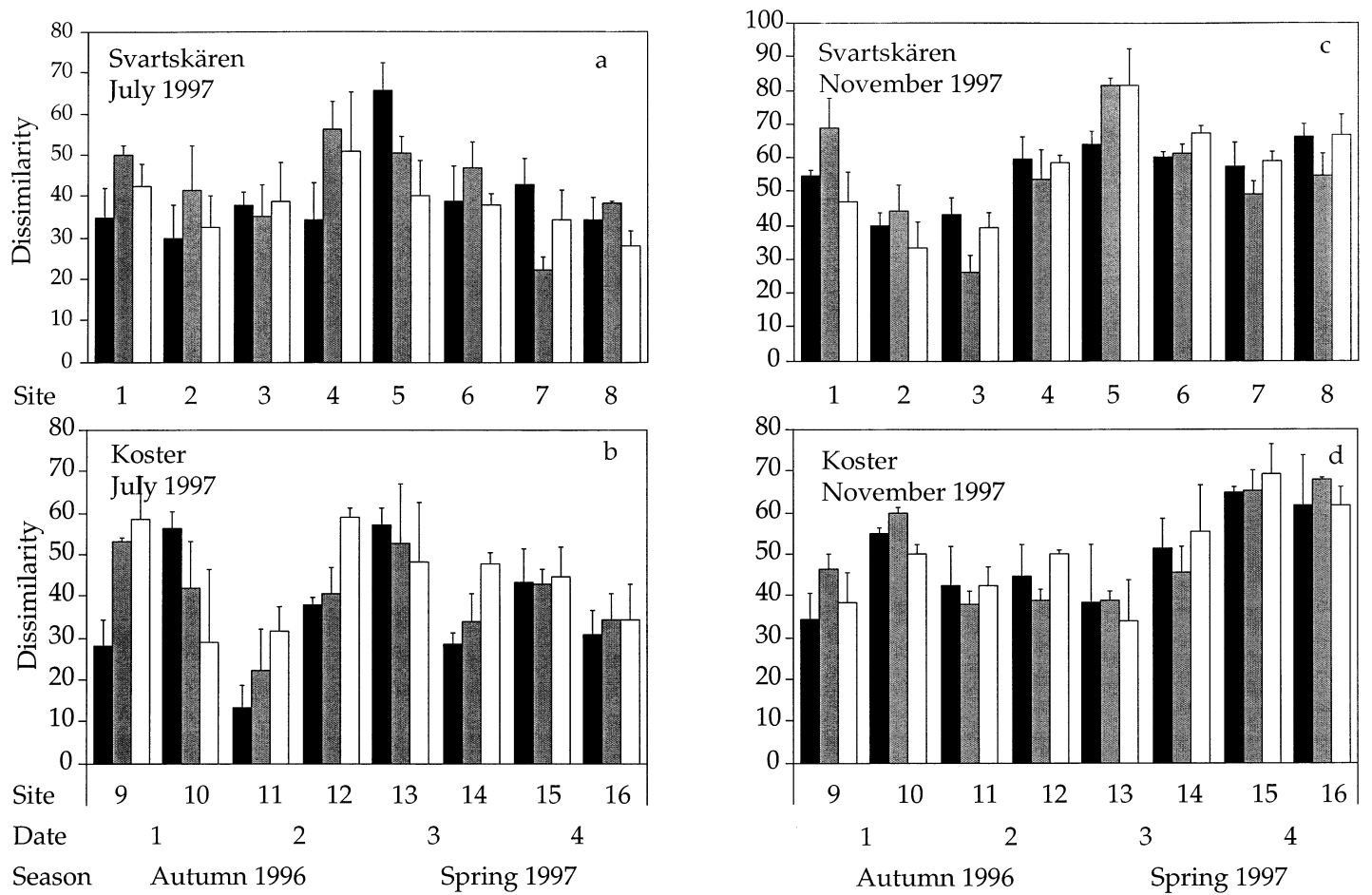

Fig. 3. Dissimilarities between samples at the start of the experiment and in (a,b) July and (c,d) November of 1997. Black columns: fenced quadrats; shaded columns: quadrats with open fences; and white columns: control quadrats $(n=3 ;$ mean \pm SE)
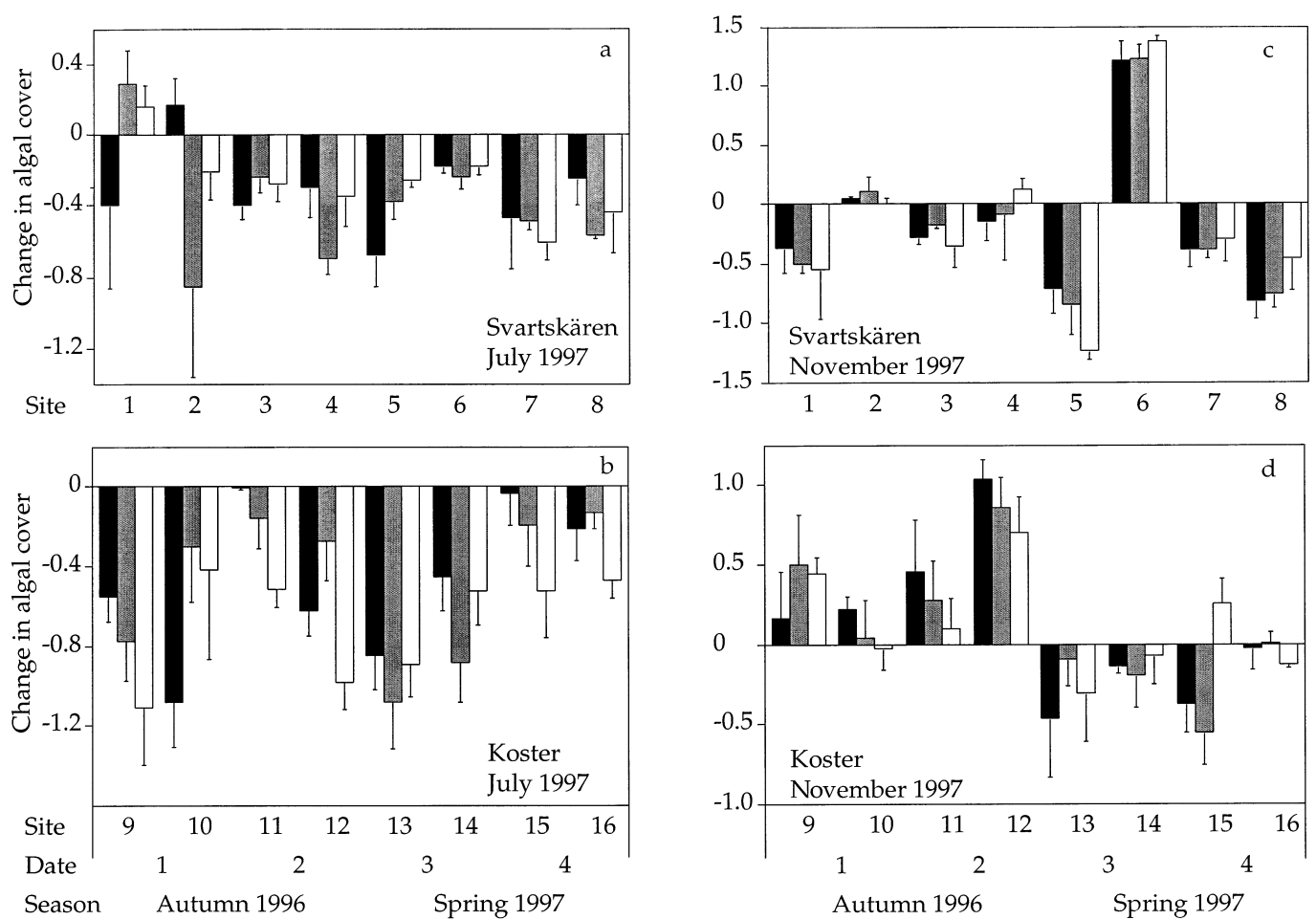

Fig. 4. Changes in the proportion of total algal cover between samples at the start of the experiment and in (a,b) July and (c,d) November of 1997. Black columns: fenced quadrats; shaded columns: quadrats with open fences; and white columns: control quadrats $(\mathrm{n}=3$; mean $\pm \mathrm{SE})$ 
of experimental treatments. No differences in the cover of crusts were detected among experimental treatments (Table 1). Variances were slightly heterogeneous for algal cover and crusts in July and for bare rock in November $(C=0.142,0.136$ and 0.219 , respectively, $\mathrm{p}<0.05)$. Because we found no evidence in support of the hypothesis that grazing affects these variables, this heterogeneity is not relevant and no further transformations were attempted.

Significant differences were thus observed among treatments for most variables at individual sites or at individual starting dates. Although these differences were generally not consistent with predictions about effects of grazing, the significant effects indicate that statistical tests were sufficiently powerful to detect effects of experimental manipulations occurring at individual sites. Nevertheless, it could arguably be informative to evaluate statistical power and qualitative consistency with predictions about differences among experimental treatments (Fig. 5). The average changes in structure of assemblages (measured by Bray-Curtis dissimilarities), total cover of algae, proportion of bare rock and cover of crusts from the start to the end of the experiment were generally not consistent with the predicted effects of grazing (i.e. $\mathrm{CO}=\mathrm{OF} \neq \mathrm{FE}$ ). Results were more often qualitatively consistent with patterns indicating experimental artifacts (i.e. $\mathrm{CO} \neq \mathrm{OF}=\mathrm{FE}$ ). Assemblages inside open fences changed more similarly to assemblages inside fences compared to those in controls in 7 of 8 instances (Fig. 5). These results indicate that artifacts from fences are greater than effects of grazing. Analyses of power of effects of grazing are therefore of limited interest.

\section{Temporal and spatial variability}

From all but one of these analyses, it is evident that assemblages changed during this experiment and that they changed differently among individual sites (Table 1). The overall magnitude of change measured as Bray-Curtis dissimilarity, as well as total cover of algae and the amount of bare rock changed differently among sites from the start of the experiment to July and November 1997 ('Si[Ar, Se, Da]' in Table 1). As an example, trajectories of assemblages at the 4 sites established at Svartskären in autumn 1996 differ among sites (Fig. 6). At the start of the experiment, 3 of these sites (Sites 1, 3 and 4) were dominated by Semibalanus balanoides and filamentous red algae Ceramium sp. and Polysiphonia sp., while the remaining site (Site 2) was dominated by $S$. balanoides, $M y$ tilus edulis and bare rock (Table 2). At the end of the experiment, the assemblages were clearly different from those at the start and different among sites (Fig. 6). The
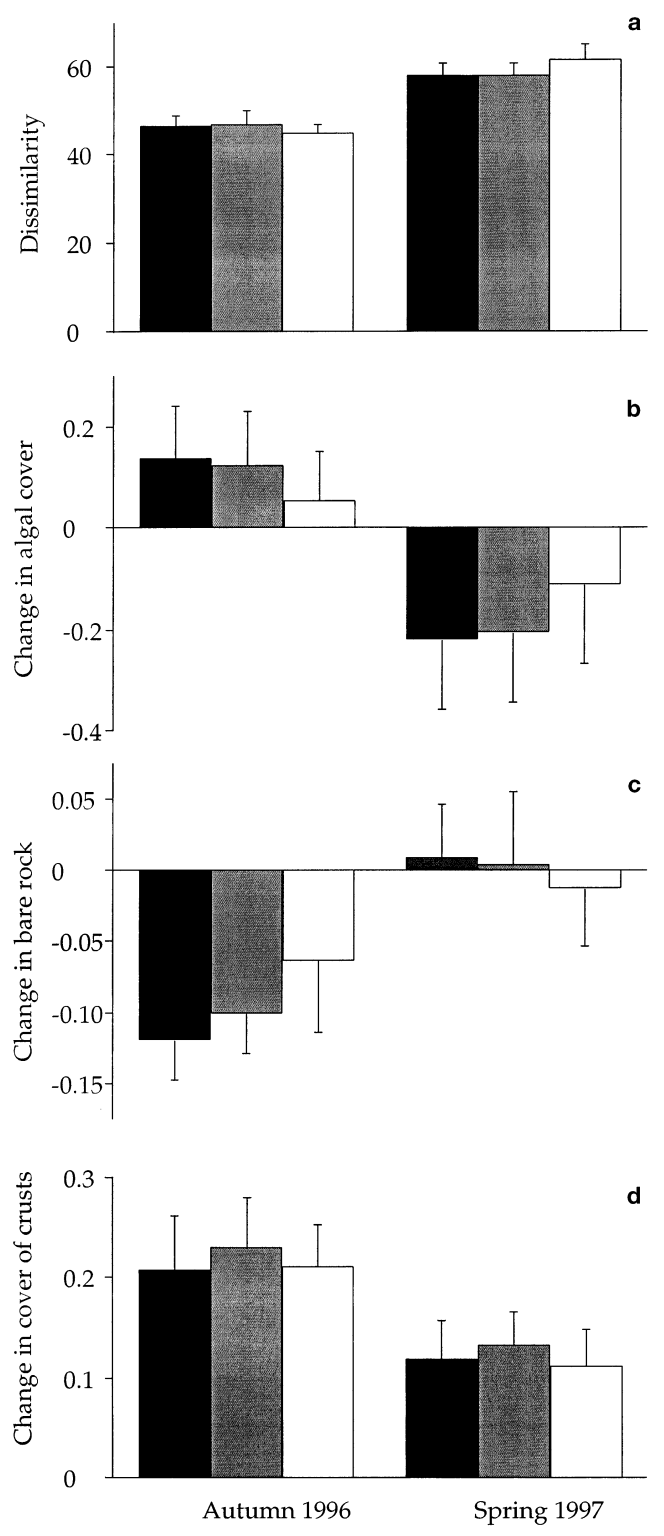

Fig. 5. Averages for each season for (a) Bray-Curtis dissimilarity, (b) change in total cover of algae, (c) change in bare rock, and (d) change in cover of crusts. Black columns: fenced quadrats; shaded columns: quadrats with open fences; and white columns: control quadrats $(n=3$; mean $\pm \mathrm{SE})$

first site was dominated by ephemeral green algae Urospora sp. and Ulothrix sp. and mussels M. edulis, the second by crusts Hildenbrandia rubra and bare rock, the third by mussels and crusts and the fourth by mussels and filamentous red algae (Table 2).

\section{DISCUSSION}

In this experiment, we tested 6 different hypotheses of how exclusion of grazers may affect assemblages of intertidal assemblages of plants and animals. Consid- 


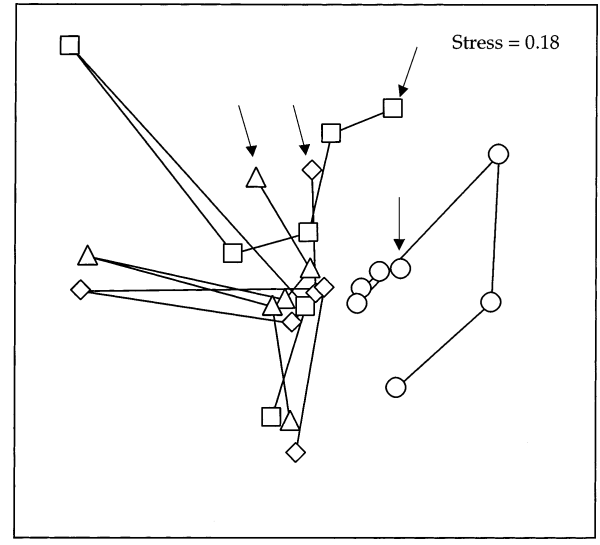

Fig. 6. n-MDS plot of temporal changes from the start to the end of the experiment at Sites 1 to 4 in Svartskären. Each symbol represents the average for all samples in the particular combination of site and time. Squares, circles, triangles and diamonds represent Sites 1, 2, 3 and 4 respectively. Arrows indicate positions at the start of the experiment and lines join the symbols in temporal sequence

erable attention was paid to the possibility that effects of grazing may differ among places and times. We predicted that if grazers were excluded from some quadrats, (1) assemblages would change differently (as measured by the Bray-Curtis dissimilarity among times), (2) total algal cover would increase, (3) the cover of crusts would increase, and (4) the amount of bare rock would decrease, relative to quadrats to which grazers had access. The results of this experiment do not provide any strong support for the model that grazing by littorinid snails plays a significant role in controlling the cover of algae or the composition of benthic assemblages on moderately exposed shores on the Swedish west coast. Evidence suggested that exclusion of grazers decreased the overall change in assemblages at 1 site (in July 1997, Site 9). Changes in algal cover differed among treatments at 3 sites in July 1997 (Sites 1, 2 and 10). Contrary to our predictions, the cover of algae decreased significantly more in fenced areas at 2 of those sites, while artifacts due to the structure of fences were suggested at the third site.

The validity of the evidence suggesting a lack of effects of grazing on these shores may have been compromised to some (unknown) degree by the fact that cages did not completely exclude small individuals of Littorina saxatilis. Quantitative observations before, during and after the experiment, however, provide additional evidence that grazing snails do not have as persistent and widespread effects on assemblages of algae on these shores as those observed in other areas on similar shores (Hawkins \& Hartnoll 1983, Hawkins et al. 1992). While these observations do not provide conclusive causal evidence, their validity is not directly dependent on successful exclusion of grazers. First, in winter 1995-1996, ice-scouring removed most algae and barnacles before the start of the experiment. This was followed by massive recruitment and growth of barnacles in the spring (pers. obs.) and subsequent recruitment of filamentous red algae (mainly Polysiphonia sp.) in the summer. Several sites, which were previously dominated by barnacles, developed a complete cover of filamentous algae. Littorinids did not prevent the recruitment and growth of filamentous algae, despite the presence of snails (pers. obs.). Second, if grazing was an important force in structuring these assemblages we would, at the end of the experiment, expect to find a large proportion of bare space and a small proportion of algal cover in plots which were accessible to grazers. For example, in a similar experiment Hawkins (1981) found approximately 10 to $20 \%$ cover of algae in uncaged plots. At the end of this experiment, however, the average cover of algae and bare rock in areas accessible to grazers was 70 and $10 \%$ respectively. Thus, it is clear that the abundance and composition of grazers commonly present on these shores is not sufficient to suppress the growth of algae to a similar degree as in other experiments. Nevertheless, it is possible that the composition of these assem-

Table 2. Average proportion (and rank) of dominant components of intertidal assemblages at the sites at Svartskären at the start (autumn 1996) and at the end (autumn 1997) of the experiment. Total covers $>1.0$ occur because the assemblages consist of several layers. -: proportion $<0.01$

\begin{tabular}{|c|c|c|c|c|c|c|c|c|c|c|}
\hline \multirow{4}{*}{$\begin{array}{l}\text { Semibalanus balanoides } \\
\text { Mytilus edulis }\end{array}$} & \multicolumn{5}{|c|}{ Start } & \multicolumn{5}{|c|}{ End } \\
\hline & Site 1 & \multicolumn{2}{|c|}{ Site 2} & Site 3 & Site 4 & Site 1 & \multicolumn{2}{|c|}{ Site 2} & Site 3 & Site 4 \\
\hline & $0.92 \quad(1)$ & 0.78 & (1) & 0.73 & $0.43 \quad(2)$ & $0.05 \quad(6)$ & 0.11 & (4) & $0.07 \quad(5)$ & 0.11 \\
\hline & $0.07 \quad(4)$ & 0.16 & (3) & 0.30 & $0.01 \quad(6)$ & $0.27 \quad(2)$ & 0.07 & (5) & $0.31 \quad(1)$ & 0.47 \\
\hline Filamentous red & $0.81 \quad(2)$ & 0.15 & (4) & $0.55 \quad(2)$ & 0.51 & $0.17 \quad(4)$ & 0.16 & (3) & $0.17 \quad(3)$ & $0.27 \quad(2)$ \\
\hline Hildenbrandia rubra & - & 0.04 & (5) & $0.10 \quad(4)$ & 0.16 & 0.18 & 0.52 & (1) & $0.25 \quad(2)$ & 0.12 \\
\hline Nemalion multifidum & $0.23 \quad(3)$ & - & - & $0.02 \quad(6)$ & 0.11 & - & - & - & - & - \\
\hline Ephemeral green & - & - & - & - & - & 0.38 & - & - & $0.13 \quad(4)$ & 0.23 \\
\hline Bare rock & $0.07 \quad(5)$ & 0.16 & (2) & $0.09 \quad(5)$ & 0.31 & 0.13 & 0.17 & (2) & $0.01 \quad(6)$ & - \\
\hline
\end{tabular}


blages may have been different had grazers not been present.

Unlike in moderately exposed shores in other parts of the world (e.g. Keser \& Larson 1984, Hartnoll \& Hawkins 1985), and unlike in more sheltered locations in this region (Lein 1980, Cervin \& Åberg 1997), grazing does not appear to significantly affect algal assemblages at these sites. The rate of grazing appears to be lower than the rates of recruitment and growth of algae occurring at mid-tide levels on these moderately exposed shores. Several models related to differences in grazing rates and rates of algal growth may be proposed to explain why the importance of grazing is smaller on these shores (Lubchenco \& Gaines 1981). Perhaps the most obvious difference between this and previous studies in which grazing has been considered important is the difference in dominant species of grazers. Although Littorina saxatilis has the potential to feed on macroscopic algae (reviewed by Norton et al. 1990), it may be that this species is less efficient than grazers which have been shown to affect assemblages elsewhere (e.g. Patella sp. and L. littorea). Alternatively, the abundance and size of individuals of $L$. saxatilis may not have been sufficient to reach combined grazing rates sufficient to balance the growth of algae. Larger abundances and average size of snails of this species may potentially affect the structure of assemblages in these areas. Another possibility is that grazing rates are lower at moderately exposed shores compared to sheltered shores, because gastropods experience more physical stress. Manipulations of densities of snails and experiments involving transplants of L. saxatilis into sheltered areas and L. littorea to moderately exposed shores could be used to test these hypotheses.

It is also possible that the effects of grazing are small on these moderately exposed shores because the algae are different from those found on sheltered shores. Littorinids have previously been shown to affect the cover of ephemeral green algae (Lein 1980, Lubchenco 1983), brown crusts (Bertness et al. 1983) and fucoids (Keser \& Larson 1984, Petraitis 1987, Cervin \& Åberg 1997). Except from occasional ephemeral green algae Urospora sp. and Ulothrix sp., neither of these groups were abundant in our experimental quadrats. The dominant types of algae encountered in this study were filamentous red algae, such as Polysiphonia sp. and Ceramium sp., and crustose red algae, mainly Hildenbrandia rubra. The lack of effect on the cover of $H$. rubra is consistent with results from earlier studies, which have shown that these algae are relatively resistant to grazing (e.g. Underwood 1980, Bertness et al. 1983). Polysiphonia sp. recruited within less than a month in the summer of 1996 and formed a complete cover in all experimental quadrats at some sites. Sub- sequently, the cover of Polysiphonia sp. was gradually overgrown by epiphytic Ceramium sp. Once the cover of algae was established, snails appeared to be practically excluded from these areas (pers. obs.). Thus, it appears that algae at these sites may have escaped grazing by settling in very large densities and by growing rapidly (cf. Lubchenco \& Gaines 1981).

In spite of problems in excluding snails, we conclude that grazing is less important on moderately exposed shores on the Swedish west coast, compared to more sheltered sites and compared to moderately exposed shores elsewhere. Experimental and observational evidence did not support the model that grazing was important in structuring these assemblages. Our observations suggest that changes in these assemblages were largely driven by seasonal changes, due to icescouring and recruitment peaks for different organisms (e.g. barnacles, filamentous red algae and mussels). Nevertheless, observations also indicated that barnacles, algae and mussels interacted in different ways at different sites: filamentous algae formed especially dense cover at some sites with large abundances of barnacles; barnacles died or grew slowly under a cover of filamentous algae, and mussels settled and replaced filamentous red algae at some sites. These are observations and models regarding processes other than grazing. Further analyses of patterns and manipulative experiments are needed to unravel the importance of these interactions.

Acknowledgements. This experiment was funded as part of the EUROROCK-project by the European Union, through contract MAS3-CT95-0012 and by the Centre for Research of Ecological Impacts of Coastal Cities. We thank P. Archambault and 3 anonymous referees for comments on earlier versions of the manuscript and J. Karlsson for providing the map.

\section{LITERATURE CITED}

Åberg P (1992) Size-based demography of the seaweed Ascophyllum nodosum in stochastic environments. Ecology 73: 1488-1501

Aleem AA (1969) Zonation, vesicle pressure and gas composition in Fucus vesiculosus and Ascophyllum nodosum at Kristineberg (west coast of Sweden). Mar Biol 4:36-43

Benedetti-Cecchi L, Cinelli F (1997) Confounding in field experiments: direct and indirect effects of artifacts due to the manipulation of limpets and macroalgae. J Exp Mar Biol Ecol 209:171-184

Bertness MD, Yund PO, Brown AF (1983) Snail grazing and the abundance of algal crusts on a sheltered New England rocky beach. J Exp Mar Biol Ecol 71:147-164

Cervin G, Åberg P (1997) Do littorinids affect the survival of Ascophyllum nodosum germlings? J Exp Mar Biol Ecol 218:35-47

Clarke KR, Warwick RM (1994) Change in marine communities: an approach to statistical analysis and interpretation. Natural Environmental Research Council, UK, Plymouth Marine Laboratory 
Foster MS (1992) How important is grazing to seaweed evolution and assemblage structure in the north-east Pacific? In: John DM, Hawkins SJ, Price JH (eds) Plant-animal interactions in the marine benthos. Clarendon Press, Oxford, p 61-85

Hartnoll RG, Hawkins SJ (1985) Patchiness and fluctuations on moderately exposed rocky shores. Ophelia 24:53-63

Hawkins SJ (1981) The influence of season and barnacles on the algal colonization of Patella vulgata exclusion areas. J Mar Biol Assoc UK 61:1-15

Hawkins SJ, Hartnoll RG (1983) Grazing of intertidal algae by marine invertebrates. Oceanogr Mar Biol Annu Rev 21: 195-282

Hawkins SJ, Hartnoll RG, Kain JM, Norton TA (1992) Plantanimal interactions on hard substrata in the north-east Atlantic. In: John DM, Hawkins SJ, Price JH (eds) Plantanimal interactions in the marine benthos. Clarendon Press, Oxford, p 1-32

Johannesson K (1989) The bare zone of the Swedish rocky shores: why is it there? Oikos 54:77-86

Keser M, Larson BR (1984) Colonization and growth dynamics of three species of Fucus. Mar Ecol Prog Ser 15:125-134

Keser M, Vadas RL, Larson BR (1981) Regrowth of Ascophyllum nodosum and Fucus vesiculosus under various harvesting regimes in Maine, USA. Bot Mar 24:29-38

Kyhlin H (1918) Svenska västkustens algregioner. Svensk Bot Tidskr 12

Lein TE (1980) The effects of Littorina littorea (Gastropoda) grazing on littoral green algae in the inner Oslofjord, Norway. Sarsia 65:87-92

Lewis JR (1965) The littoral fringe on rocky coasts of southern Norway and western Sweden. Proc 5th Mar Biol Symp Botanica Gothoburgensia 3:129-143

Lubchenco J (1978) Plant species diversity in a marine intertidal community: importance of herbivore food preference and algal competitive abilities. Am Nat 112:23-39

Lubchenco J (1983) Littorina and Fucus: effects of herbivores, substratum heterogeneity, and plant escapes during succession. Ecology 64:1116-1123

Lubchenco J, Gaines SD (1981) A unified approach to marine

Editorial responsibility: Tony Underwood (Contributing

Editor), Sydney, New South Wales, Australia plant-herbivore interactions. I. Populations and communities. Annu Rev Ecol Syst 12:405-437

Norton TA, Hawkins SJ, Manley NL, Williams GA, Watson DC (1990) Scraping a living: a review of littorinid grazing. Hydrobiologia 193:117-138

Petraitis PS (1983) Grazing patterns of the periwinkle and their effect on sessile intertidal organisms. Ecology 64: 522-533

Petraitis PS (1987) Factors organizing rocky intertidal communities of New England: herbivory and predation in sheltered bays. J Exp Mar Biol Ecol 109:117-136

Raffaelli DG, Hughes RN (1978) The effects of crevice size and availability on populations of Littorina rudis and Littorina neritoides. J Anim Ecol 47:71-83

Söderström J (1965) Vertical zonation of littoral algae in Bohuslän. Acta Phytogeogr Suec 50:85-91

Underwood AJ (1980) The effects of grazing by gastropods and physical factors on the upper limits of distribution of intertidal algae. Oecologia 46:201-213

Underwood AJ (1997) Experiments in ecology — their logical design and interpretation using analysis of variance. Cambridge University Press, Cambridge

Underwood AJ, Anderson MJ (1994) Seasonal and temporal aspects of recruitment and succession in an intertidal estuarine assemblage. J Mar Biol Assoc UK 74:563-584

Underwood AJ, Chapman MG (1996) Scales of spatial patterns of distribution of intertidal invertebrates. Oecologia 107:212-224

Underwood AJ, Jernakoff P (1981) Effects of interactions between algae and grazing gastropods on the structure of a low-shore intertidal community. Oecologia 48: $221-233$

Vadas RL, Elner RW (1992) Plant-animal interactions in the north-west Atlantic. In: John DM, Hawkins SJ, Price JH (eds) Plant-animal interactions in marine benthos. Clarendon Press, Oxford, p 33-60

Viejo RM, Åberg P, Cervin G, Lindegarth M (1999) The interactive effects of adult canopy, germling density and grazing on germling survival of the rockweed Ascophyllum nodosum. Mar Ecol Prog Ser 187:113-120

Submitted: January 13, 2000; Accepted: September 6, 2000 Proofs received from author(s): February 15, 2001 